\title{
Increased intramyocellular lipid content but normal skeletal muscle mitochondrial oxidative capacity throughout the pathogenesis of type 2 diabetes.
}

Citation for published version (APA):

Feyter, H. M., Lenaers, E., Houten, S. M., Schrauwen, P., Hesselink, M. K., Wanders, R. J., Nicolay, K., \& Prompers, J. J. (2008). Increased intramyocellular lipid content but normal skeletal muscle mitochondrial oxidative capacity throughout the pathogenesis of type 2 diabetes. Faseb Journal, 22(11), 3947-3955. https://doi.org/10.1096/fj.08-112318

Document status and date:

Published: 01/01/2008

DOI:

10.1096/fj.08-112318

Document Version:

Publisher's PDF, also known as Version of record

Document license:

Taverne

Please check the document version of this publication:

- A submitted manuscript is the version of the article upon submission and before peer-review. There can be important differences between the submitted version and the official published version of record.

People interested in the research are advised to contact the author for the final version of the publication, or visit the DOI to the publisher's website.

- The final author version and the galley proof are versions of the publication after peer review.

- The final published version features the final layout of the paper including the volume, issue and page numbers.

Link to publication

\footnotetext{
General rights rights.

- You may freely distribute the URL identifying the publication in the public portal. please follow below link for the End User Agreement:

www.umlib.nl/taverne-license

Take down policy

If you believe that this document breaches copyright please contact us at:

repository@maastrichtuniversity.nl

providing details and we will investigate your claim.
}

Copyright and moral rights for the publications made accessible in the public portal are retained by the authors and/or other copyright owners and it is a condition of accessing publications that users recognise and abide by the legal requirements associated with these

- Users may download and print one copy of any publication from the public portal for the purpose of private study or research.

- You may not further distribute the material or use it for any profit-making activity or commercial gain

If the publication is distributed under the terms of Article $25 \mathrm{fa}$ of the Dutch Copyright Act, indicated by the "Taverne" license above, 


\title{
Increased intramyocellular lipid content but normal skeletal muscle mitochondrial oxidative capacity throughout the pathogenesis of type 2 diabetes
}

\author{
Henk M. De Feyter, ${ }^{*}, 1$ Ellen Lenaers, ${ }^{\dagger}$ Sander M. Houten, ${ }^{\S}$ Patrick Schrauwen, ${ }^{\ddagger}$ \\ Matthijs K. Hesselink, ${ }^{\dagger}$ Ronald J. A. Wanders, ${ }^{\S}$ Klaas Nicolay,* \\ and Jeanine J. Prompers* \\ *Biomedical NMR, Department of Biomedical Engineering, Eindhoven University of Technology, \\ Eindhoven, The Netherlands; ${ }^{\dagger}$ Department of Human Movement Sciences and ${ }^{\dagger}$ Department \\ of Human Biology, Nutrition and Toxicology Research Institute Maastricht, Maastricht University, \\ Maastricht, The Netherlands; and ${ }^{\$}$ Department of Clinical Chemistry, Laboratory Genetic Metabolic \\ Diseases, Academic Medical Center, Amsterdam, The Netherlands
}

ABSTRACT Currently inherited or acquired skeletal muscle mitochondrial dysfunction is linked to dysregulated fatty acid metabolism, resulting in increased levels of intramyocellular lipids (IMCLs) and lipid intermediates, inducing insulin resistance. The present study aimed to clarify the order of changes in IMCL levels and skeletal muscle mitochondrial function during the development of type 2 diabetes in Zucker diabetic fatty (ZDF) rats. IMCL levels and skeletal muscle oxidative capacity were determined in vivo, using localized ${ }^{1} \mathbf{H}$ magnetic resonance spectroscopy (MRS) and dynamic ${ }^{31} \mathrm{P}$ MRS, respectively. In parallel, in vitro activities were measured from enzymes involved in fatty acid oxidation, the tricarboxylic acid cycle and the electron transport chain. Fa/fa ZDF rats were studied at 3 different ages corresponding to different stages of type 2 diabetes, whereas fa/ + rats served as controls. Fa/fa ZDF rats had higher IMCL contents than controls throughout the duration of the study. In vivo muscle oxidative capacity was not different in fa/fa animals compared to controls, and in vitro enzyme activity data suggested improved functionality of enzymes involved in fat oxidation in type 2 diabetic animals. Accordingly, we can conclude that in the ZDF rat model, type 2 diabetes develops in the absence of skeletal muscle mitochondrial dysfunction.-De Feyter, H. M., Lenaers, E., Houten, S. M., Schrauwen, P., Hesselink, M. K., Wanders, R. J. A., Nicolay, K., Prompers, J. J. Increased intramyocellular lipid content but normal skeletal muscle mitochondrial oxidative capacity throughout the pathogenesis of type 2 diabetes. FASEB J. 22, 3947-3955 (2008)

Key Words: rat $\cdot$ NMR spectroscopy $\cdot$ In vivo NMR $\cdot$ insulin resistance $\cdot P C r$ recovery

SKELETAL MUSCLE ACCOUNTS FOR the great majority of insulin-stimulated glucose uptake (1), and insulin resistance of skeletal muscle tissue is one of the earliest detectable disturbances in the development of type 2 diabetes [reviewed by Petersen and Shulman (2)]. It has been shown that insulin sensitivity is negatively correlated with the amount of intramyocellular lipids (IMCLs) stored inside skeletal muscle cells. This relationship has been described in sedentary humans (3-6) as well as in rat models of insulin resistance and type 2 diabetes (7-9). A causal relationship between IMCL accumulation and insulin resistance has never been demonstrated, but there are strong indications that intermediates of lipid metabolism, such as long-chain acyl-CoAs, diacylglycerol, and/or ceramides impede the insulin signaling rather than the stored triglycerides themselves $(10,11)$.

Recently, insulin resistance has also been associated with skeletal muscle mitochondrial dysfunction (12, 13). Data originating from in vivo magnetic resonance spectroscopy (MRS) measurements (14-17), in vitro enzyme activity assays (18-21), and expression analysis of genes involved in oxidative metabolism (22, 23) suggest that skeletal muscle mitochondrial dysfunction plays a role in insulin resistance and type 2 diabetes. Current hypotheses link inherited or acquired mitochondrial dysfunction to impaired fatty acid metabolism, which subsequently results in increased levels of IMCLs and lipid intermediates, inducing insulin resistance $(2,13-15,24)$.

Studies in humans investigating the relations among mitochondrial function, IMCLs, and insulin resistance or type 2 diabetes have been carried out using crosssectional study designs. Because these studies only provide correlative information, it is impossible to unravel cause and consequence. In an attempt to bypass these limitations, we studied an established animal model of type 2 diabetes, the Zucker diabetic fatty (ZDF) rat, aiming to

\footnotetext{
${ }^{1}$ Correspondence and current address: Yale University, MRRC, TAC N 136, 300 Cedar St., PO Box 208043, New Haven, CT 06520-8043, USA. E-mail: henk.defeyter@yale.edu doi: 10.1096/fj.08-112318
} 
clarify the order in which changes in IMCLs and in vivo skeletal muscle mitochondrial function occur during the development of type 2 diabetes. Localized ${ }^{1} \mathrm{H}$ MRS was used to determine IMCL content, and dynamic ${ }^{31} \mathrm{P}$ MRS was applied in combination with a minimally invasive electrical stimulation method to measure postexercise resynthesis kinetics of phosphocreatine (PCr). The postexercise PCr recovery time constant provides a measure of in vivo muscle oxidative capacity because the muscle contractions create a highly activated state of the mitochondria (i.e., high ADP levels) and ATP used to restore the PCr pool during recovery is originating exclusively from mitochondrial oxidative phosphorylation (25).

$\mathrm{Fa} / \mathrm{fa} \mathrm{ZDF}$ rats were studied in vivo in a longitudinal study design at ages corresponding to 1) a normoglycemic-hyperinsulinemic state (prediabetic), 2) a hyperglycemic-hyperinsulinemic state (overt type 2 diabetes), and 3) a late type 2 diabetes stage characterized by hyperglycemia and progressive $\beta$-cell failure (26). Heterozygous $\mathrm{fa} /+$ rats remain normoglycemic and normoinsulinemic and served as controls (26). In addition, muscle tissue was collected from parallel groups of animals at the same time points as the in vivo MRS measurements to measure in vitro activities of enzymes/ complexes of $\beta$-oxidation, tricarboxylic acid (TCA) -cycle, and electron transport chain (ETC) in homogenized muscle samples.

Based on phenotypical characteristics of fa/fa rats, we hypothesized that the development of overt type 2 diabetes in $\mathrm{fa} / \mathrm{fa}$ rats would be paralleled by a progressive loss of in vivo mitochondrial oxidative capacity and increase in IMCL content compared to the control $\mathrm{fa} /+$ rats. Similarly, in vitro enzyme activities were expected to progressively decrease in $\mathrm{fa} / \mathrm{fa}$ rats with advancing type 2 diabetes.

\section{MATERIALS AND METHODS}

\section{Animals}

Male obese ZDF rats (ZDF/Gmi, fa/fa; $n=22)$ and lean littermates $(\mathrm{ZDF} / \mathrm{Gmi}, \mathrm{fa} /+; n=23)$ (Charles River Laboratories, The Netherlands) were housed in pairs at $20^{\circ} \mathrm{C}$ and $50 \%$ humidity, on a 12-h light-dark cycle with ad libitum access to water and chow during the entire study. Animals arrived at the laboratory at $5 \mathrm{wk}$ of age. From $7 \mathrm{wk}$ of age, animals received a diet containing, as percentage of calories, $16.7 \%$ fat, $56.4 \%$ carbohydrates and $26.8 \%$ protein (Altromin, Lage, Germany). Body weight and food intake were monitored weekly. Principles of laboratory animal care were followed and all experimental procedures were approved by the Animal Ethics Committee of Maastricht University.

\section{MRS groups}

In $10 \mathrm{fa} / \mathrm{fa}$ and $11 \mathrm{fa} /+$ animals, IMCL levels and skeletal muscle oxidative capacity were measured in tibialis anterior (TA) muscle by applying in vivo ${ }^{1} \mathrm{H}$ and ${ }^{31} \mathrm{P}$ MRS, respectively, at 6,12 , and 18 wk of age. In the week after the last MRS experiments (19 wk of age), the animals were killed and muscle tissue was harvested according to procedures described for the parallel groups.

\section{Parallel groups}

Parallel to the MRS measurements, ZDF rats were killed at 6 $(\mathrm{fa} / \mathrm{fa}, n=6 ; \mathrm{fa} /+, n=6)$ and $12(\mathrm{fa} / \mathrm{fa}, n=6 ; \mathrm{fa} /+, n=6)$ wk of age by cervical dislocation within $20 \mathrm{~s}$ following $\mathrm{CO}_{2}$ sedation. TA muscles were excised, and midbelly portions were rapidly frozen in liquid nitrogen and stored at $-80^{\circ} \mathrm{C}$.

\section{MRS}

All MRS measurements were performed on a $6.3 \mathrm{~T}$ horizontal Bruker MR system (Bruker, Ettlingen, Germany). During preparatory surgical procedures and MRS experiments, animals were anesthetized using $1-2 \%$ isoflurane (Forene; Abbot $\mathrm{GmbH}$, Wiesbaden, Germany) administered via a face mask with medical air $(0.4 \mathrm{~L} / \mathrm{min})$, and body temperature was maintained at $37 \pm 1^{\circ} \mathrm{C}$ using heating pads. In the MR scanner, respiration was monitored using a pressure sensor registering thorax movement (Rapid Biomedical, Rimpar, Germany).

Single-voxel localized ${ }^{1} \mathrm{H}$ MRS was applied to measure IMCL levels in TA, as described elsewhere (27) except that no additional outer volume suppression was used. In short, 2 voxels of $2 \times 2 \times 2 \mathrm{~mm}^{3}$ were subsequently measured in white (ventral) and red (dorsal) TA, respectively, using an ellipsoid ${ }^{1} \mathrm{H}$ surface coil $(18 / 22 \mathrm{~mm})$. The ${ }^{1} \mathrm{H}$ MR spectra were acquired using the LASER (localization by adiabatic selective refocusing) sequence (28) [repetition time $\mathrm{TR}=1 \mathrm{~s}$, echo time $\mathrm{TE}=16 \mathrm{~ms}$, SWAMP (sequence for water suppression with adiabatic modulated pulses) water suppression (29), 512 averages].

${ }^{31} \mathrm{P}$ MRS was applied using a combination of a circular ${ }^{1} \mathrm{H}$ surface coil $(40 \mathrm{~mm})$ and an ellipsoid ${ }^{31} \mathrm{P}$ surface coil $(10 / 18$ $\mathrm{mm}$ ) positioned over the TA. Localized shimming was performed on the water signal using the ${ }^{1} \mathrm{H}$ surface coil. ${ }^{31} \mathrm{P}$ spectra were acquired applying an adiabatic excitation pulse with a flip angle of $90^{\circ}$. A fully relaxed spectrum $(\mathrm{TR}=20 \mathrm{~s}, 32$ averages) and a partially saturated spectrum $(\mathrm{TR}=5 \mathrm{~s}, 128$ averages) were measured at rest, followed by the acquisition of a time series of spectra ( $\mathrm{TR}=5 \mathrm{~s}, 4$ averages) before, during, and after electrical stimulation of TA. Electrical stimulation was applied via acute, subcutaneously implanted platinum electrodes positioned along the distal nerve trajectory of the $\mathrm{n}$. peroneus communis to induce contractions in the TA. A time series consisted of $3 \mathrm{~min}$ rest, $2 \mathrm{~min}$ of electrical stimulation, and $10 \mathrm{~min}$ of recovery. Stimulation pulse length was $100 \mathrm{~ms}$, frequency was $80 \mathrm{~Hz}$, stimulation voltage varied between 2 and $4 \mathrm{~V}$, and pulses were applied $1 / \mathrm{s}$. For each rat, at each age at least 3 consecutive time series were performed. During the first time series, stimulation voltage was adjusted to assure significant depletion of $\mathrm{PCr}$ in subsequent time series. The latter 2 time series were used for analysis of $\mathrm{PCr}$ recovery kinetics.

Both ${ }^{31} \mathrm{P}$ and ${ }^{1} \mathrm{H}$ MR spectra were fit in the time domain by using a nonlinear least squares algorithm in the jMRUI software package $(30) .{ }^{1} \mathrm{H}$ MR spectra were fit as described elsewhere (27). IMCL was then expressed relative to total creatine $(\mathrm{tCr})$. For the ${ }^{31} \mathrm{P}$ MR spectra recorded at rest, $\mathrm{PCr}$ and the intra- and extracellular inorganic phosphate $(\mathrm{Pi})$ peaks (31) were fit to Lorentzian line shapes. The $\alpha$ - and $\gamma$-ATP peaks were fit to Gaussian line shapes with equal peak areas. Due to limited bandwidth of the excitation pulse, the $\beta$-ATP had lower amplitude and was not fit. In ${ }^{31} \mathrm{P}$ MR spectra from the time series, peaks from intra- and extracellular $\mathrm{Pi}$ could not be distinguished; therefore, a single Pi peak was fit 
to a Gaussian line shape. Absolute concentrations of the phosphorylated metabolites were calculated after correction for partial saturation with the assumption that the ATP concentration is $8.2 \mathrm{mM}$ at rest (32). Intracellular $\mathrm{pH}$ was calculated from the chemical shift difference between the $\mathrm{Pi}$ and PCr resonances (33). The free cytosolic ADP concentration was calculated from the $\mathrm{PCr}$ concentration and $\mathrm{pH}$ using a creatine kinase equilibrium constant $\left(K_{\mathrm{eq}}\right)$ of $1.66 \times 10^{9}$ $\mathrm{M}^{-1}$ (34) and the assumption that $15 \%$ of the total creatine is unphosphorylated at rest (35). For the time series, the PCr line width during recovery was constrained to the average $\mathrm{PCr}$ line width during recovery (excluding the first 5 data points) obtained from a prior, unconstrained fit. The data of $\mathrm{PCr}$ resynthesis were fit to a monoexponential function using Matlab (version 6.5, Mathworks, Natick, MA, USA) yielding a time constant $\tau_{\mathrm{PCr}}$, which is a measure of skeletal muscle mitochondrial oxidative capacity. Two time series with similar end-exercise $\mathrm{pH}$ values were analyzed for each animal, resulting in 2 values of $\tau_{\mathrm{PCr}}$, which were averaged.

\section{In vitro enzyme activities}

Muscle tissue (frozen microtome section) was disrupted using sonication (twice at 8-W output, $40 \mathrm{~J}$, on ice) in homogenization buffer $(50 \mathrm{mM}$ Tris, $120 \mathrm{mM} \mathrm{NaCl}, 5 \mathrm{mM} \mathrm{KCl}, 1 \mathrm{mM}$ $\mathrm{MgSO}_{4}, 1 \mathrm{mM} \mathrm{CaCl}$, and $10 \%$ glycerol, $\left.\mathrm{pH} 7.4\right)$. The homogenates were centrifuged for $5 \mathrm{~min}$ at $1000 \mathrm{~g}$. Protein concentration was determined in the supernatant using the Bradford method. The homogenates were diluted to $\sim 1$ $\mathrm{mg} / \mathrm{mL}$. Very long chain acyl-CoA dehydrogenase (VLCAD) activity was measured as described elsewhere, using palmitoylCoA as substrate (36). The production of trans-2,3-palmitoylCoA and L-3-hydroxypalmitoyl-CoA was quantified by HPLC and used to calculate acyl-CoA dehydrogenase activity. Citrate synthase (CS) was measured spectrophotometrically at 412 $\mathrm{nm}$ by the formation of free CoA using 5,5'-dithio-bis-(2nitrobenzoic acid) (37). Succinate dehydrogenase (SDH) was measured using a method described by Munujos et al. (38). Cytochrome $c$ oxidase (complex IV) activity was measured by following the formation of oxidized cytochrome $c$ at $550 \mathrm{~nm}$ using a method described by Cooperstein and Lazarow (39).

\section{Plasma parameters}

Blood samples were collected from animals via the retroorbital plexus at 6,12 , and $18 \mathrm{wk}$ of age, under isoflurane anesthesia, after $4 \mathrm{~h}$ of food deprivation (randomly $n=6$ / genotype). The blood samples were collected in K-EDTA coated tubes and centrifuged for $10 \mathrm{~min}$ at $1000 \mathrm{~g}$, and plasma aliquots were frozen in liquid nitrogen and stored at $-80^{\circ} \mathrm{C}$. Plasma glucose content was determined using the hexokinase method (Roche, Basel, Switzerland), and free fatty acids (FFAs) were measured with the Wako NEFA C test kit (Wako Chemicals, Neuss, Germany). Fasting plasma insulin concentrations were determined using an ultrasensitive solid phase two-site ELISA kit (Mercodia, Uppsala, Sweden).

\section{Statistical analysis}

Data are presented as means $\pm \mathrm{SD}$. MRS data were analyzed using ANOVA for repeated measures with 1 within-subjects factor (age) and 1 between-subjects factor (genotype). Bonferroni corrected post hoc tests were carried out in order to identify differences between different ages. Two-way ANOVA was used to analyze the metabolic plasma parameters and the in vitro enzyme activities. When there was a significant effect of the interaction term age $\times$ genotype, data were analyzed again using the relevant ANOVA for each genotype separately to detect effects of age. Independent sample $t$ tests were used at different ages to detect differences between genotypes. All tests were performed two-sided using SPSS 14.0 (SPSS Inc, Chicago, IL, USA), and statistical significance was set at $P \leq$ 0.05 .

\section{RESULTS}

\section{Animal model}

Body weight was higher in $\mathrm{fa} / \mathrm{fa}$ than in $\mathrm{fa} /+$ rats during the entire study ( $P<0.001$ at every time point). $\mathrm{Fa} / \mathrm{fa}$ rats had a higher body weight at the start of the study and appeared to increase in body weight at a higher rate than fa/ + animals between week 6 and 11 . Ad libitum food intake of fa/fa rats was higher than that of $\mathrm{fa} /+$ rats over the entire study duration $(P<0.001$ at every time point).

Plasma concentrations of glucose, insulin, and FFAs determined at 6, 12, and 18 wk of age are depicted in Fig. 1. For both glucose and insulin, there was a significant age $\times$ genotype interaction $(P<0.001$ and $P=0.04$, respectively), which was attributable to the age-related changes in $\mathrm{fa} / \mathrm{fa}$ rats. $\mathrm{Fa} /+$ animals displayed normal and constant glucose and insulin levels throughout the entire study (Fig. 1a,b). At all ages, the glucose and insulin levels were significantly higher in a

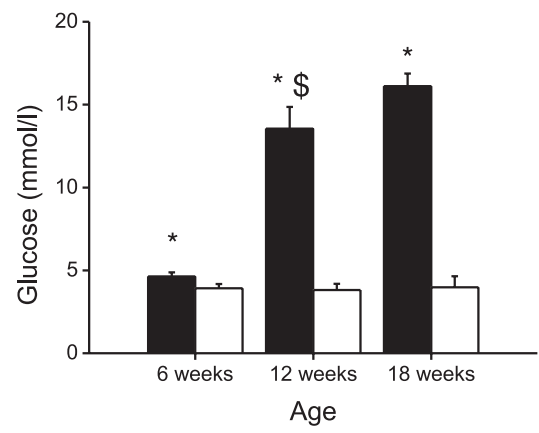

b

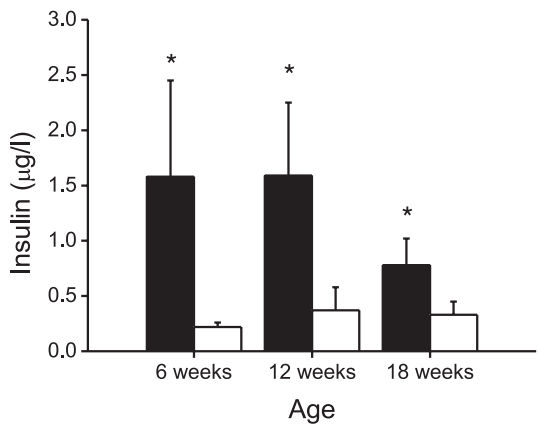

C

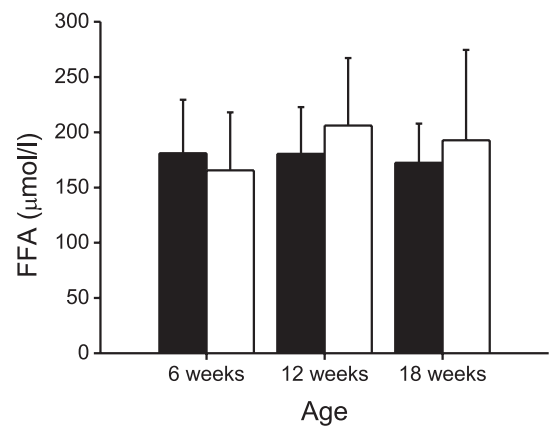

Figure 1. Fasting plasma concentrations of glucose $(a)$, insulin $(b)$, and FFA $(c)$ at 6 , 12, and 18 wk of age. Filled bars, fa/fa rats; open bars, fa/ + rats. ${ }^{*} P<0.05$ vs. fa/ + rats of the same age; $\$ P<0.05$ vs. 6 - and 18 -wk-old fa/fa rats. Error bars represent SD. 
$\mathrm{fa} / \mathrm{fa}$ rats compared to controls $(P<0.001$ for glucose and $P<0.05$ for insulin). The plasma data confirm that at 6 wk of age, $\mathrm{fa} / \mathrm{fa}$ animals were euglycemic-hyperinsulinemic (prediabetic); at $12 \mathrm{wk}, \mathrm{fa} / \mathrm{fa}$ animals were diabetic, displaying hyperglycemia and hyperinsulinemia; and at 18 wk, they were in an advanced diabetic state, with hyperglycemia but decreased insulin levels compared to $12 \mathrm{wk}$. Both genotypes showed similar and constant plasma FFA levels during the period of the study (Fig. 1c).

\section{IMCLs}

Figure $2 \boldsymbol{a}, \boldsymbol{b}$ shows representative examples of ${ }^{1} \mathrm{H}$ MR spectra measured in red TA of a fa/fa and a fa/ + rat, respectively, at the age of 12 wk. The spectra clearly depict the increased amplitude of the IMCL resonances measured in the $\mathrm{fa} / \mathrm{fa}$ rat compared to the control $\mathrm{fa} /+$ rat. The mean IMCL levels at different ages for white and red regions of the TA muscle are presented in Fig. $2 c, d$, respectively. In both genotypes and at all ages, IMCL levels were $\sim 2-3$ times higher in the red region of the TA compared to the white region. There was a significant age $\times$ genotype interaction effect for IMCLs in both red and white regions of the TA muscle. Analyzing the age effect on IMCL levels within each genotype separately showed a trend toward a decrease $(P=0.077)$ in white TA and a significant decrease in red TA $(P<0.01)$ of $\mathrm{fa} /+$ animals. In contrast, IMCL levels significantly increased in $\mathrm{fa} / \mathrm{fa}$ rats between 6 and $12 \mathrm{wk}$ of age (red and white TA, both $P<0.01$ ), and decreased again between 12 and 18 wk of age in white TA
$(P=0.012)$, and tended to decrease in red TA $(P=0.09)$. IMCL levels were significantly higher in $\mathrm{fa} / \mathrm{fa}$ rats compared to $\mathrm{fa} /+$ animals for both the white and red region of the TA at all ages (all $P<0.05)$. Compared to the euglycemic-hyperinsulinemic state (6 wk of age), the difference in IMCL content was amplified in the hyperglycemic-hyperinsulinemic state (12 wk of age), and IMCL levels remained much higher in fa/fa rats compared to $\mathrm{fa} /+$ animals in the advanced diabetic state.

\section{${ }^{31} \mathbf{P}$ MRS}

Table 1 lists the ${ }^{31} \mathrm{P}$ metabolite concentrations and $\mathrm{pH}$ at rest. The intracellular $\mathrm{Pi}$ concentration $[\mathrm{Pi}]$ and $[\mathrm{Pi}] /[\mathrm{PCr}]$ was higher in $\mathrm{fa} / \mathrm{fa}$ rats than in $\mathrm{fa} /+$ rats (both $P<0.001$ ) at all time points. Both parameters were changing during maturation in both genotypes: [Pi] increased between 12 and $18 \mathrm{wk}$ of age $(P<0.001)$, and $[\mathrm{Pi}] /[\mathrm{PCr}]$ decreased between 6 and 12 wk of age $(P=0.023)$, but increased again between 12 and $18 \mathrm{wk}$ of age $(P<0.001)$. There was also an effect of aging in both genotypes on $[\mathrm{PCr}],[\mathrm{ADP}]$, and $\mathrm{pH}$, which all increased from 6 to 12 wk of age ([PCr] and $[\mathrm{ADP}]$ : $P<0.001$; $\mathrm{pH}: P=0.001)$, but remained constant during further maturation.

Figure $3 \boldsymbol{a}$ shows a stack plot of spectra measured during a rest-exercise-recovery protocol and demonstrates how the PCr signal drops when the electrical stimulation starts, reaches a steady state, and then recovers when ceasing stimulation. End-exercise metabolite concentrations and $\mathrm{pH}$ are presented in Table 2.
Figure 2. Examples of water-suppressed ${ }^{1} \mathrm{H}$ MR spectra measured in red TA from a 12-wk-old $\mathrm{fa} / \mathrm{fa}(a)$ and $\mathrm{fa} /+(b)$ rat. Peak annotations: $\mathrm{H}_{2} \mathrm{O}$, residual water; EMCL, extramyocellular lipids. IMCL content at different ages in white $(c)$ and red TA $(d)$. Filled bars, fa/fa rats; open bars, $\mathrm{fa} /+$ rats. $* P<0.05$ vs. fa/fa rats of the same age; $\$ P<0.05$ vs. 6 -wk-old rats of same genotype; ${ }^{\#} P<0.05$ vs. 12-wk-old fa/fa rats. Error bars represent SD. a

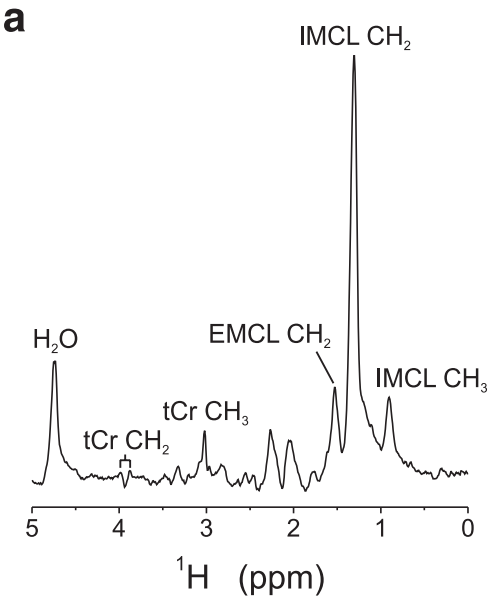

C

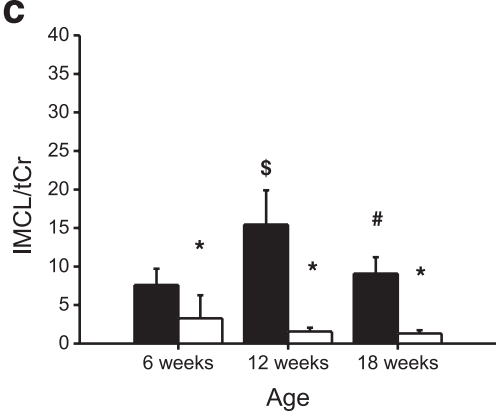

b

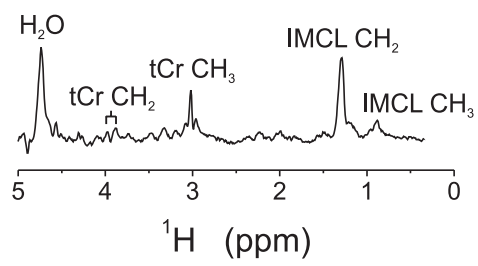

d

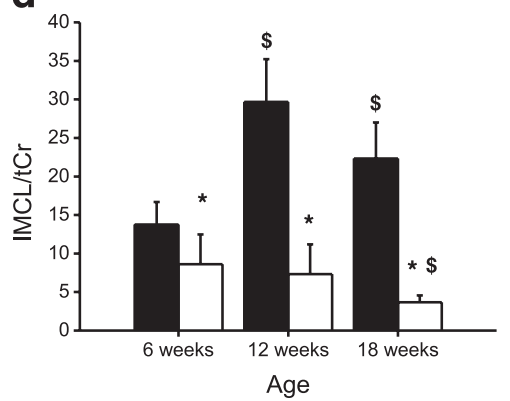




\begin{tabular}{|c|c|c|c|c|c|c|}
\hline \multirow[b]{2}{*}{ Measure } & \multicolumn{2}{|c|}{$6 \mathrm{wk}$} & \multicolumn{2}{|c|}{$12 \mathrm{wk}$} & \multicolumn{2}{|c|}{$18 \mathrm{wk}$} \\
\hline & $\mathrm{fa} / \mathrm{fa}$ & $\mathrm{fa} /+$ & $\mathrm{fa} / \mathrm{fa}$ & $\mathrm{fa} /+$ & $\mathrm{fa} / \mathrm{fa}$ & $\mathrm{fa} /+$ \\
\hline$[\mathrm{PCr}\rceil(\mathrm{mM})$ & $31.7 \pm 1.2$ & $32.5 \pm 1.5$ & $40.2 \pm 1.2^{b}$ & $38.5 \pm 1.0^{b}$ & $39.1 \pm 2.0^{b}$ & $39.5 \pm 1.6^{b}$ \\
\hline$[\mathrm{Pi}](\mathrm{mM})^{a}$ & $3.2 \pm 0.7$ & $2.5 \pm 0.6$ & $3.1 \pm 0.7$ & $2.3 \pm 0.5$ & $4.3 \pm 0.6^{c}$ & $3.3 \pm 0.6^{c}$ \\
\hline$[\mathrm{Pi}] /[\mathrm{PCr}]^{a}$ & $0.1 \pm 0.02$ & $0.08 \pm 0.02$ & $0.08 \pm 0.02^{b}$ & $0.06 \pm 0.01^{b}$ & $0.11 \pm 0.02^{c}$ & $0.08 \pm 0.02^{c}$ \\
\hline$[\mathrm{ADP}](\mu \mathrm{M})$ & $9.6 \pm 1.6$ & $9.9 \pm 1.6$ & $12.0 \pm 0.4^{b}$ & $11.4 \pm 0.5^{b}$ & $11.3 \pm 0.5$ & $11.7 \pm 0.7$ \\
\hline $\mathrm{pH}$ & $7.04 \pm 0.08$ & $7.05 \pm 0.07$ & $7.14 \pm 0.02^{b}$ & $7.12 \pm 0.02^{b}$ & $7.11 \pm 0.02$ & $7.13 \pm 0.03$ \\
\hline
\end{tabular}

${ }^{a}$ Significantly different between genotypes. ${ }^{b}$ Significantly different compared to 6-wk-old animals. ${ }^{c}$ Significantly different compared to 12-wk-old animals.

End-exercise [Pi] was higher in $\mathrm{fa} / \mathrm{fa}$ than in $\mathrm{fa} /+$ animals. The other metabolite's concentrations were similar in both genotypes. End-exercise [PCr], [ADP], and $\mathrm{pH}$ were higher at $12 \mathrm{wk}$ compared to $6 \mathrm{wk}$ of age, which can most probably be attributed to the applied electrical stimulation protocol. At 12 wk of age, (erroneously) slightly less strenuous contractions were induced, explaining the differences in end-exercise [PCr], $[\mathrm{ADP}]$, and $\mathrm{pH}$. At each age, however, end-exercise $\mathrm{pH}$ did not differ between genotypes.

Figure $3 b$ depicts an example of the PCr recovery fit. The mean $R^{2}$ for the fit procedure of the individual recovery datasets was $0.96 \pm 0.03$. The mean $\mathrm{PCr}$ recovery time constants of both genotypes at different ages are depicted in Fig. 3c. Repeated-measures ANOVA revealed no significant effect of genotype or genotype $X$ age on $\tau_{\mathrm{PCr}}$. However, in both genotypes, there was a significant effect of age; that is, at $12 \mathrm{wk} \tau_{\mathrm{PCr}}$ was greater than at $6 \mathrm{wk}$, and at $18 \mathrm{wk} \tau_{\mathrm{PCr}}$ was greater than at $12 \mathrm{wk}$ (all $P<0.001$ ), indicating a significant decrease in muscle in vivo oxidative capacity with aging.

\section{In vitro enzyme assays}

We measured activities of VLCAD (Fig. 4a), CS (Fig. 4b), SDH (Fig. 4c), and complex IV (Fig. $4 d$ ) in the different
ZDF genotypes at different ages in order to evaluate mitochondrial function in vitro. The statistical analysis of VLCAD activities revealed a borderline significance $(P=0.06)$ for the interaction of age and genotype and a significant effect of genotype $(P=0.001)$ : higher VLCAD activities were measured in $\mathrm{fa} / \mathrm{fa}$ animals compared to $\mathrm{fa} /+$ rats at 12 and $19 \mathrm{wk}$ of age (Fig. $4 a$ ). CS activities displayed a significant genotype effect $(P=0.045)$ in the ANOVA, which became weaker in the post hoc comparisons: at $19 \mathrm{wk}$ of age, fa/fa rats showed a trend for higher CS activity compared to fa $/+$ rats $(P=0.075)$ (Fig. $4 b)$. SDH enzyme activities did not differ between genotypes and also remained unchanged with age (Fig. $4 c$ ). The statistical analysis of complex IV activities illustrated a significant effect of both genotype and age. Complex IV activity was higher in 6-wk-old fa/fa rats compared to control rats (Fig. $4 d$ ). Complex IV activity decreased in both genotypes, but to a lesser extent in $\mathrm{fa} / \mathrm{fa}$ rats, resulting in higher enzyme activity in 19-wk-old fa/fa rats compared to controls.

\section{DISCUSSION}

The present study aimed to clarify the order in which changes in IMCL content and skeletal muscle mito-

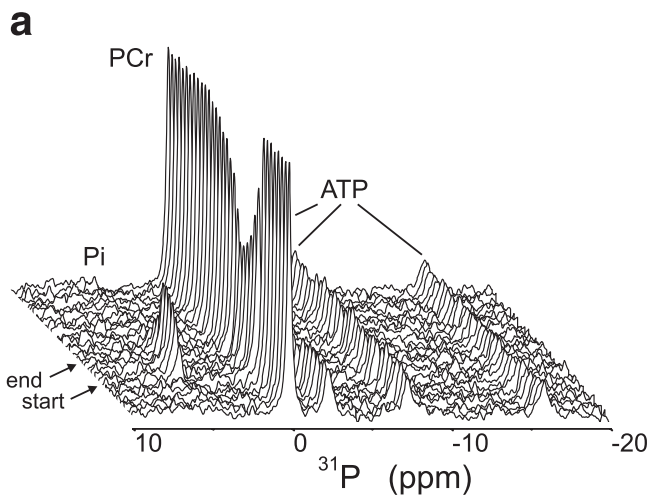

b

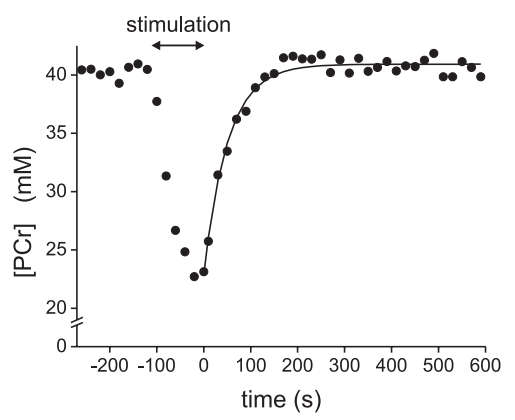

C

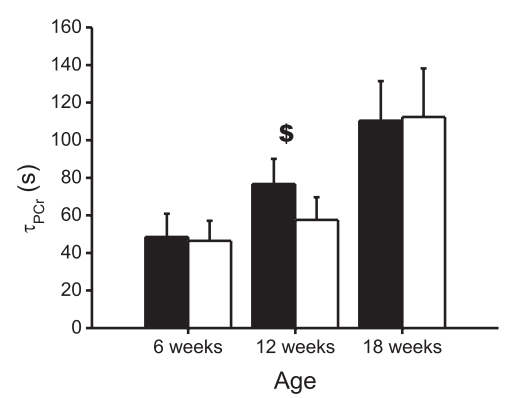

Figure 3. a) Stack plot of ${ }^{31} \mathrm{P}$ MR spectra measured in TA during a time series of a 12-wk-old fa/ + rat during a rest-exercise-recovery protocol. Contractions were induced by electrical stimulation. The period of electrical stimulation (2 min) is indicated with the arrows (start and stop). Time resolution=20 s. Peaks are from Pi, PCr, and ATP. b) [PCr] during rest-exercise-recovery protocol. Recovery data were fit with a monoexponential function (black line); $\tau_{\mathrm{PCr}}=51.1 \mathrm{~s} . c$ ) Average $\tau_{\mathrm{PCr}}$ of fa/fa (filled bars) and fa/ + rats (open bars) at different ages. A higher value of $\tau_{\mathrm{PCr}}$ indicates a lower oxidative capacity. $\$ P<0.05$ vs. 6 - and 18 -wk-old rats. Error bars represent SD. 


\begin{tabular}{|c|c|c|c|c|c|c|}
\hline \multirow[b]{2}{*}{ Measure } & \multicolumn{2}{|c|}{$6 \mathrm{wk}$} & \multicolumn{2}{|c|}{$12 \mathrm{wk}$} & \multicolumn{2}{|c|}{$18 \mathrm{wk}$} \\
\hline & $\mathrm{fa} / \mathrm{fa}$ & $\mathrm{fa} /+$ & $\mathrm{fa} / \mathrm{fa}$ & $\mathrm{fa} /+$ & $\mathrm{fa} / \mathrm{fa}$ & $\mathrm{fa} /+$ \\
\hline$[\mathrm{PCr}](\mathrm{mM})$ & $16.7 \pm 2.3$ & $17.0 \pm 2.3$ & $21.4 \pm 2.3^{b}$ & $19.9 \pm 2.0^{b}$ & $19.5 \pm 1.7^{b}$ & $21.8 \pm 1.6^{b}$ \\
\hline$[\mathrm{Pi}](\mathrm{mM})^{a}$ & $21.1 \pm 3.7$ & $17.7 \pm 1.8$ & $20.5 \pm 3.7$ & $15.8 \pm 2.4$ & $22.5 \pm 4.4$ & $17.6 \pm 2.9$ \\
\hline$[\mathrm{ADP}](\mu \mathrm{M})$ & $47.3 \pm 16.4$ & $53.4 \pm 19.3$ & $57.9 \pm 9.06^{b}$ & $67.2 \pm 9.8^{b}$ & $59.2 \pm 13.0$ & $51.3 \pm 10.9$ \\
\hline $\mathrm{pH}$ & $6.86 \pm 0.11$ & $6.91 \pm 0.07$ & $6.98 \pm 0.08^{b}$ & $7.02 \pm 0.10^{b}$ & $6.93 \pm 0.02$ & $6.96 \pm 0.06$ \\
\hline
\end{tabular}

${ }^{a}$ Significantly different between genotypes. ${ }^{b}$ Significantly different compared to 6 -wk-old animals.

chondrial function occur during the development of type 2 diabetes in ZDF rats. We hypothesized that in vivo mitochondrial oxidative capacity and in vitro activities of enzymes involved in oxidative metabolism would show a progressive decrease parallel to the development of type 2 diabetes. Furthermore, IMCL levels were expected to increase during the development of type 2 diabetes. IMCL levels were higher in prediabetic fa/fa rats than in controls and increased in $\mathrm{fa} / \mathrm{fa}$ rats with the development of type 2 diabetes. Although IMCL content did not continue to rise between 12 and $18 \mathrm{wk}$ of age, IMCL levels were always higher in $\mathrm{fa} / \mathrm{fa}$ rats compared to control animals. In agreement with our hypothesis, in vivo mitochondrial oxidative capacity progressively decreased throughout the duration of the study, as evidenced by the increased time constant for $\mathrm{PCr}$ recovery after exercise. However, since this occurred to a similar degree in both ZDF genotypes, the decreased oxidative capacity did not seem to play a major role in the development of type 2 diabetes in the $\mathrm{fa} / \mathrm{fa}$ rats. In accordance with the in vivo measurements, in vitro enzyme activities were not decreased in $\mathrm{fa} / \mathrm{fa}$ rats compared to control animals at any age. VLCAD and complex IV activities were even higher, and CS activity tended to be higher in late-stage diabetic $\mathrm{fa} / \mathrm{fa}$ rats than in control $\mathrm{fa} /+$ rats.

The in vivo IMCL measurements confirm previous results on muscle fiber type-related levels of IMCLs within Wistar rat TA muscle (27), as in both ZDF genotypes IMCL levels were 2-3 times higher in red TA compared to white TA. Relative changes in IMCL levels during the study were similar in white and red TA, both in $\mathrm{fa} / \mathrm{fa}$ and in $\mathrm{fa} /+$ rats. In general, the age-dependent changes in IMCL content of ZDF rats are in good agreement with earlier reports (8).

At $6 \mathrm{wk}$ of age, in vivo skeletal muscle oxidative capacity was identical in both genotypes despite the hyperinsulinemic state of $\mathrm{fa} / \mathrm{fa}$ rats. This implies that hyperinsulinemia develops without skeletal muscle mitochondrial dysfunction in the 6-wk-old $\mathrm{fa} / \mathrm{fa}$ rats. During the transition from the normoglycemic-hyperinsulinemic state toward the hyperglycemic-hyperinsulinemic state, $\tau_{\mathrm{PCr}}$ in $\mathrm{fa} / \mathrm{fa}$ rats gradually increased, resulting in about 3 times higher values at $18 \mathrm{wk}$ compared to 6 wk of age. However, a similar change in $\tau_{\mathrm{PCr}}$ was observed in maturing normoglycemic-normoinsulinemic $\mathrm{fa} /+$ rats. Therefore, this decrease in oxidative capacity can most likely be entirely attributed to
Figure 4. Activities of VLCAD $(a)$, CS $(b)$, SDH $(c)$, and complex IV $(d)$ in the different ZDF genotypes at different ages. Activities were determined in 6 animals/group. $* P<0.05$ vs. fa/ + rats of the same age; ${ }^{\#} P<0.05$ vs. 6-wk-old animals of same genotype; ${ }^{\$} P<0.05$ vs. 12 -wkold animals of same genotype. Error bars represent SD. a

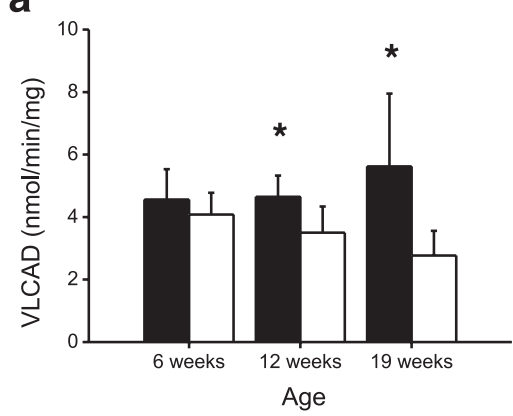

C

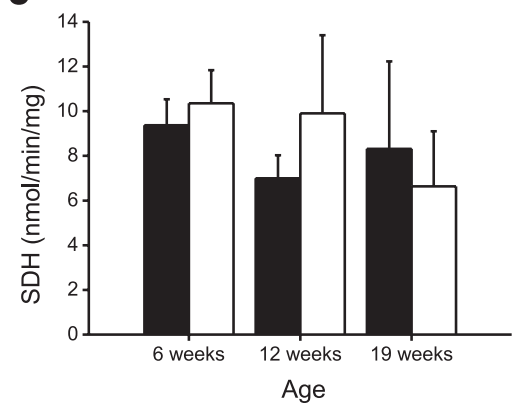

b

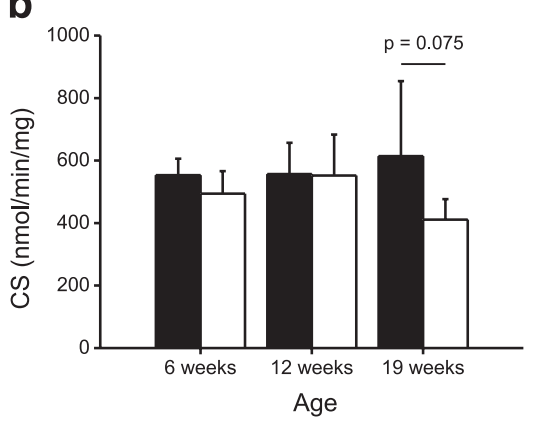

d

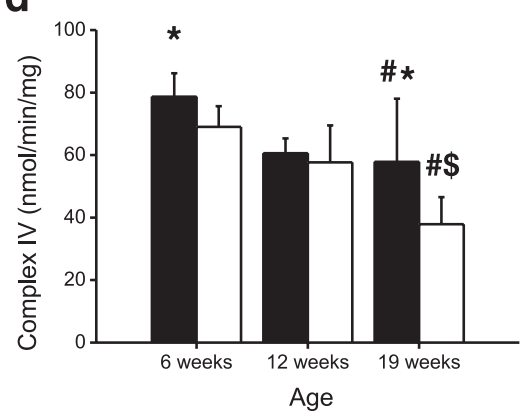


aging of the animals. Healthy Wistar rats display a similar degree of age-related decrease in oxidative capacity, and $\tau_{\mathrm{PCr}}$ values of the TA are similar to those measured in ZDF rats (data not shown). Thus, our data do not reveal apparent mitochondrial dysfunction in the diabetic ZDF phenotype. On the other hand, we cannot completely exclude that the combination of both the age-related decrease of in vivo mitochondrial oxidative capacity and high IMCL levels contributed to the development of type 2 diabetes.

Sanderson et al. (40) measured PCr recovery kinetics in 15-wk-old, obese, insulin-resistant Zucker rats. There were no differences observed in $\tau_{\mathrm{PCr}}$ between obese Zucker rats and lean controls; CS activities were also the same (40). In contrast, Klein et al. (41) reported slower postexercise recovery of $\mathrm{PCr}$ in obese Zucker rats compared to lean controls. However, their ${ }^{31} \mathrm{P}$ MR spectra were recorded with relatively low time resolution (2 min), which impeded a robust quantitative analysis of the recovery data. Furthermore, the endexercise $\mathrm{pH}$ was significantly lower in the obese animals, which does not allow comparison of the PCr recovery rates between both animal groups, as was also argued by the authors (41).

To study diet-induced alterations in skeletal muscle mitochondrial function, Chanseaume et al. (42) fed Wistar rats a high-fat diet and sacrificed them at sequential time points. Measuring in vitro mitochondrial respiration and ATP production in skinned muscle fibers, they found no differences in the TA muscle of Wistar rats fed a high-fat diet compared with control animals, which is in agreement with our results. However, in a later stage, after 40 days of consuming a high-fat diet, the soleus muscle showed a decrease in oxidative phosphorylation activity (42). In young Wistar rats fed a high-fat diet for 15 days, increased lipid oxidative capacity was measured in muscle homogenates and subsarcolemmal and intermyofibrillar mitochondria (43). More recently, however, the same group showed that a longer period ( $7 \mathrm{wk}$ ) of high-fat diet consumption in adult rats resulted in a lower respiratory capacity of subsarcolemmal mitochondria (44). The duration of the diet and the age of the animals at the start of the intervention have been proposed as factors accountable for these different results in Wistar rats $(44,45)$. In diet-induced insulin-resistant mice, skeletal muscle mitochondrial function was not affected after $4 \mathrm{wk}$ of diet. However, after 16 wk of high-fat and high-sucrose diet, reactive oxygen species (ROS) induced mitochondrial dysfunction (46). The data from these diet-induced diabetic mice suggest that mitochondrial alterations do not precede insulin resistance and result from increased ROS production in muscle (46). Although we have studied relatively long-term effects of insulin resistance and type 2 diabetes, we cannot exclude that at older age, a decreased in vivo oxidative capacity might develop in $\mathrm{fa} / \mathrm{fa}$ rats secondary to longer exposure to overt type 2 diabetes.

Although PCr recovery analysis provides an excellent measure of in vivo mitochondrial oxidative capacity in general, it does not offer information about the pattern of substrates utilized by the mitochondrial respiratory chain. Keeping in mind the short duration of the muscle contraction protocol, it is fair to assume that the oxidative phosphorylation during contraction and recovery relies predominantly on carbohydrates as a fuel. Differences in fat oxidative capacity that do not lead to a general dysfunction of the mitochondria will therefore remain undetected in postexercise $\mathrm{PCr}$ recovery analysis. However, in vitro VLCAD activity did not show an impairment in $\mathrm{fa} / \mathrm{fa}$ animals, either. Rather, the opposite occurred, as we observed a significant upregulation of VCLAD activity in $\mathrm{fa} / \mathrm{fa}$ rats compared to control rats at 12 and $19 \mathrm{wk}$ of age. Furthermore, at any age, in vitro activities of CS, SDH, and complex IV were similar or increased in $\mathrm{fa} / \mathrm{fa}$ rats compared to $\mathrm{fa} /+$ rats, pointing toward overall normal functioning of mitochondrial machinery. The in vitro data are in agreement with Turner et al. (47), who studied various rodent models of high-fat-diet-induced insulin resistance and measured increased activity of medium-chain acylCoA dehydrogenase (another enzyme of the $\beta$-oxidation, comparable to VLCAD) and increased activity of $\mathrm{CS}$ in $\mathrm{fa} / \mathrm{fa}$ rats. In addition, they reported increased in vitro fatty acid oxidative capacity in muscle homogenates and isolated mitochondria (47). Also, protein expression of peroxisome proliferator-activated receptor $\gamma$ coactivator (PGC) $-1 \alpha$, a strong activator of mitochondrial biogenesis and oxidative metabolism, and several mitochondrial respiratory chain complexes were found to be up-regulated. Both in vivo and in vitro data of the present study are in line with these findings, as high IMCL accumulation in $\mathrm{fa} / \mathrm{fa}$ rats does not seem to be induced by decreased muscle mitochondrial oxidative capacity. In accordance, 8 wk of high-fat diet consumption in Wistar rats resulted in increased IMCL levels but did not affect intrinsic mitochondrial functioning (45).

Genetic models of obesity and insulin resistance are, in general, characterized by an early-established phenotype. The ZDF rat model allows studying the transition from insulin resistance toward overt type 2 diabetes, but not investigation of the mechanisms involved in the development of insulin resistance itself, as the latter is presumably already present in 6-wk-old animals (26). Longitudinal in vivo studies of animal models of slowly progressing skeletal muscle insulin resistance are expected to give crucial insights into the role of mitochondrial oxidative capacity in that pathological condition.

Studies in animal models of lipid-induced insulin resistance do not exclude the possibility that an intrinsic defect in the skeletal muscle fatty acid oxidative machinery might lead to accumulation of triglycerides and fatty acid metabolites and thereby induce insulin resistance. Dobbins et al. (7) showed that inhibiting carnitine palmitoyltransferase-1, thereby blocking the entry of fatty acids into mitochondria, resulted in increased IMCL content, decreased whole-body insulin sensitivity, and decreased glucose disposal in skeletal muscle of 
rats. On the other hand, long-chain acyl-CoA dehydrogenase (48) and PGC-1 $\alpha$ knockout mice (49) did not show any signs of decreased insulin sensitivity of skeletal muscle tissue. Remarkably, two mouse models characterized by progressive loss of respiratory chain function and activity even showed improved glucose homeostasis and skeletal muscle insulin sensitivity (50, 51). Even more surprisingly, reduced mitochondrial activity made these mice resistant to diabetes and obesity (51). Whether these transgenic mouse models generated compensatory mechanisms protecting them from developing insulin resistance remains to be elucidated.

\section{CONCLUSIONS}

We used minimally invasive MRS methods to collect unique longitudinal data of in vivo mitochondrial oxidative capacity and IMCL levels in ZDF rats at different stages throughout the development of type 2 diabetes. Despite increased IMCL levels, in vivo mitochondrial oxidative capacity did not differ between diabetic and control animals, neither in the prediabetic state nor during full-blown type 2 diabetes. The in vivo MRS results were corroborated by in vitro enzyme activity data, suggesting even an improved capacity of enzymes involved in fat oxidation in the type 2 diabetic animals. Accordingly, we can conclude that in the ZDF rat model, the transition from insulin resistance to type 2 diabetes does occur in the absence of skeletal muscle mitochondrial dysfunction.

We express our appreciation to Stephan Majoor and Larry de Graaf for their assistance with the in vivo experiments and for technical support, respectively. We thank Jos P. N. Ruiter for technical assistance with the enzyme assays and Robin A. de Graaf for help with the implementation of the LASER pulse sequence. M.K.H. is supported by a VIDI grant for innovative research $(917.66 .359)$.

\section{REFERENCES}

1. DeFronzo, R. A., Jacot, E., Jequier, E., Maeder, E., Wahren, J., and Felber, J. P. (1981) The effect of insulin on the disposal of intravenous glucose. Results from indirect calorimetry and hepatic and femoral venous catheterization. Diabetes 30, 10001007

2. Petersen, K. F., and Shulman, G. I. (2006) Etiology of insulin resistance. Am. J. Med. 119, S10-S16

3. Goodpaster, B. H., He, J., Watkins, S., and Kelley, D. E. (2001) Skeletal muscle lipid content and insulin resistance: evidence for a paradox in endurance-trained athletes. J. Clin. Endocrinol. Metab. 86, 5755-5761

4. Krssak, M., Falk Petersen, K., Dresner, A., DiPietro, L., Vogel, S. M., Rothman, D. L., Roden, M., and Shulman, G. I. (1999) Intramyocellular lipid concentrations are correlated with insulin sensitivity in humans: a $1 \mathrm{H}$ NMR spectroscopy study. Diabetologia 42, 113-116

5. Pan, D. A., Lillioja, S., Kriketos, A. D., Milner, M. R., Baur, L. A., Bogardus, C., Jenkins, A. B., and Storlien, L. H. (1997) Skeletal muscle triglyceride levels are inversely related to insulin action. Diabetes 46, 983-988
6. Perseghin, G., Scifo, P., De Cobelli, F., Pagliato, E., Battezzati, A., Arcelloni, C., Vanzulli, A., Testolin, G., Pozza, G., Del Maschio, A., and Luzi, L. (1999) Intramyocellular triglyceride content is a determinant of in vivo insulin resistance in humans: a 1H-13C nuclear magnetic resonance spectroscopy assessment in offspring of type 2 diabetic parents. Diabetes 48, 1600-1606

7. Dobbins, R. L., Szczepaniak, L. S., Bentley, B., Esser, V., Myhill, J., and McGarry, J. D. (2001) Prolonged inhibition of muscle carnitine palmitoyltransferase-1 promotes intramyocellular lipid accumulation and insulin resistance in rats. Diabetes 50, 123-130

8. Kuhlmann, J., Neumann-Haefelin, C., Belz, U., Kalisch, J., Juretschke, H. P., Stein, M., Kleinschmidt, E., Kramer, W., and Herling, A. W. (2003) Intramyocellular lipid and insulin resistance: a longitudinal in vivo $1 \mathrm{H}$-spectroscopic study in Zucker diabetic fatty rats. Diabetes 52, 138-144

9. Kuhlmann, J., Neumann-Haefelin, C., Belz, U., Kramer, W., Juretschke, H. P., and Herling, A. W. (2005) Correlation between insulin resistance and intramyocellular lipid levels in rats. Magn. Reson. Med. 53, 1275-1282

10. Shulman, G. I. (2000) Cellular mechanisms of insulin resistance. J. Clin. Invest. 106, 171-176

11. Yu, C., Chen, Y., Cline, G. W., Zhang, D., Zong, H., Wang, Y., Bergeron, R., Kim, J. K., Cushman, S. W., Cooney, G. J., Atcheson, B., White, M. F., Kraegen, E. W., and Shulman, G. I. (2002) Mechanism by which fatty acids inhibit insulin activation of insulin receptor substrate-1 (IRS-1)-associated phosphatidylinositol 3-kinase activity in muscle. J. Biol. Chem. 277, 5023050236

12. Rabol, R., Boushel, R., and Dela, F. (2006) Mitochondrial oxidative function and type 2 diabetes. Appl. Physiol. Nutr. Metab. 31, 675-683

13. Lowell, B. B., and Shulman, G. I. (2005) Mitochondrial dysfunction and type 2 diabetes. Science 307, 384-387

14. Petersen, K. F., Befroy, D., Dufour, S., Dziura, J., Ariyan, C., Rothman, D. L., DiPietro, L., Cline, G. W., and Shulman, G. I. (2003) Mitochondrial dysfunction in the elderly: possible role in insulin resistance. Science 300, 1140-1142

15. Petersen, K. F., Dufour, S., Befroy, D., Garcia, R., and Shulman, G. I. (2004) Impaired mitochondrial activity in the insulinresistant offspring of patients with type 2 diabetes. N. Engl. J. Med. 350, 664-671

16. Schrauwen-Hinderling, V. B., Kooi, M. E., Hesselink, M. K., Jeneson, J. A., Backes, W. H., van Echteld, C. J., van Engelshoven, J. M., Mensink, M., and Schrauwen, P. (2007) Impaired in vivo mitochondrial function but similar intramyocellular lipid content in patients with type 2 diabetes mellitus and BMI-matched control subjects. Diabetologia 50, 113-120

17. Befroy, D. E., Petersen, K. F., Dufour, S., Mason, G. F., de Graaf, R. A., Rothman, D. L., and Shulman, G. I. (2007) Impaired mitochondrial substrate oxidation in muscle of insulin-resistant offspring of type 2 diabetic patients. Diabetes 56, 1376-1381

18. Simoneau, J. A., and Kelley, D. E. (1997) Altered glycolytic and oxidative capacities of skeletal muscle contribute to insulin resistance in NIDDM. J. Appl. Physiol. 83, 166-171

19. He, J., Watkins, S., and Kelley, D. E. (2001) Skeletal muscle lipid content and oxidative enzyme activity in relation to muscle fiber type in type 2 diabetes and obesity. Diabetes 50, 817-823

20. Kelley, D. E., He, J., Menshikova, E. V., and Ritov, V. B. (2002) Dysfunction of mitochondria in human skeletal muscle in type 2 diabetes. Diabetes 51, 2944-2950

21. Ritov, V. B., Menshikova, E. V., He, J., Ferrell, R. E., Goodpaster, B. H., and Kelley, D. E. (2005) Deficiency of subsarcolemmal mitochondria in obesity and type 2 diabetes. Diabetes 54, 8-14

22. Mootha, V. K., Lindgren, C. M., Eriksson, K. F., Subramanian, A., Sihag, S., Lehar, J., Puigserver, P., Carlsson, E., Ridderstrale, M., Laurila, E., Houstis, N., Daly, M. J., Patterson, N., Mesirov, J. P., Golub, T. R., Tamayo, P., Spiegelman, B., Lander, E. S., Hirschhorn, J. N., Altshuler, D., and Groop, L. C. (2003) PGC-1alpha-responsive genes involved in oxidative phosphorylation are coordinately downregulated in human diabetes. Nat. Genet. 34, 267-273

23. Patti, M. E., Butte, A. J., Crunkhorn, S., Cusi, K., Berria, R., Kashyap, S., Miyazaki, Y., Kohane, I., Costello, M., Saccone, R., Landaker, E. J., Goldfine, A. B., Mun, E., DeFronzo, R., Finlayson, J., Kahn, C. R., and Mandarino, L. J. (2003) Coordinated reduction of genes of oxidative metabolism in 
humans with insulin resistance and diabetes: potential role of PGC1 and NRF1. Proc. Natl. Acad. Sci. U. S. A. 100, 84668471

24. Roden, M. (2005) Muscle triglycerides and mitochondrial function: possible mechanisms for the development of type 2 diabetes. Int. J. Obes. (London) 29 (Suppl. 2), S111-S115

25. Quistorff, B., Johansen, L., and Sahlin, K. (1993) Absence of phosphocreatine resynthesis in human calf muscle during ischaemic recovery. Biochem. J. 291(Pt. 3), 681-686

26. Etgen, G. J., and Oldham, B. A. (2000) Profiling of Zucker diabetic fatty rats in their progression to the overt diabetic state. Metabolism 49, 684-688

27. De Feyter, H. M., Schaart, G., Hesselink, M. K., Schrauwen, P., Nicolay, K., and Prompers, J. J. (2006) Regional variations in intramyocellular lipid concentration correlate with muscle fiber type distribution in rat tibialis anterior muscle. Magn. Reson. Med. 56, 19-25

28. Garwood, M., and DelaBarre, L. (2001) The return of the frequency sweep: designing adiabatic pulses for contemporary NMR. J. Magn. Reson. 153, 155-177

29. De Graaf, R. A., and Nicolay, K. (1998) Adiabatic water suppression using frequency selective excitation. Magn. Reson. Med. 40 , $690-696$

30. Vanhamme, L., van den Boogaart, A., and Van Huffel, S. (1997) Improved method for accurate and efficient quantification of MRS data with use of prior knowledge. J. Magn. Reson. 129, $35-43$

31. Brindle, K. M., Blackledge, M. J., Challiss, R. A., and Radda, G. K. (1989) 31P NMR magnetization-transfer measurements of ATP turnover during steady-state isometric muscle contraction in the rat hind limb in vivo. Biochemistry 28, 4887-4893

32. Taylor, D. J., Styles, P., Matthews, P. M., Arnold, D. A., Gadian, D. G., Bore, P., and Radda, G. K. (1986) Energetics of human muscle: exercise-induced ATP depletion. Magn. Reson. Med. 3, $44-54$

33. Taylor, D. J., Bore, P. J., Styles, P., Gadian, D. G., and Radda, G. K. (1983) Bioenergetics of intact human muscle. A 31P nuclear magnetic resonance study. Mol. Biol. Med. 1, 77-94

34. Lawson, J. W., and Veech, R. L. (1979) Effects of $\mathrm{pH}$ and free $\mathrm{Mg} 2+$ on the Keq of the creatine kinase reaction and other phosphate hydrolyses and phosphate transfer reactions. J. Biol. Chem. 254, 6528-6537

35. Boska, M. (1994) ATP production rates as a function of force level in the human gastrocnemius/soleus using 31P MRS. Magn. Reson. Med. 32, 1-10

36. Wanders, R. J., Vreken, P., den Boer, M. E., Wijburg, F. A., van Gennip, A. H., and Ijlst, L. (1999) Disorders of mitochondrial fatty acyl-CoA beta-oxidation. J. Inherit. Metab. Dis. 22, 442-487

37. Srere, P. A., Brazil, H., and Gonen, L. (1963) The citratecondensing enzyme of pigeon breast muscle and moth flight muscle. Acta Chem. Scand. 17, S129-134

38. Munujos, P., Coll-Cantí, J., González-Sastre, F., and Gella, F. J. (1993) Assay of succinate dehydrogenase activity by a colorimetric-continuous method using iodonitrotetrazolium chloride as electron acceptor. Anal. Biochem. 212, 506-509

39. Cooperstein, S. J., and Lazarow, A. (1951) A microspectrophotometric method for the determination of cytochrome oxidase. J. Biol. Chem. 189, 665-670
40. Sanderson, A. L., Kemp, G. J., Thompson, C. H., and Radda, G. K. (1996) Increased oxidative and delayed glycogenolytic ATP synthesis in exercising skeletal muscle of obese (insulinresistant) Zucker rats. Clin. Sci. (London) 91, 691-702

41. Klein, M., Kaminsky, P., Walker, P. M., Straczek, J., Barbe, F., Duc, M., and Burlet, C. (1994) Muscle bioenergetics in obese Zucker rats. Am. J. Physiol. 266, E410-E417

42. Chanseaume, E., Tardy, A. L., Salles, J., Giraudet, C., Rousset, P. Tissandier, A., Boirie, Y., and Morio, B. (2007) Chronological approach of diet-induced alterations in muscle mitochondrial functions in rats. Obesity (Silver Spring) 15, 50-59

43. Iossa, S., Mollica, M. P., Lionetti, L., Crescenzo, R., Botta, M., and Liverini, G. (2002) Skeletal muscle oxidative capacity in rats fed high-fat diet. Int. J. Obes. Relat. Metab. Disord. 26, 65-72

44. Lionetti, L., Mollica, M. P., Crescenzo, R., D'Andrea, E., Ferraro, M., Bianco, F., Liverini, G., and Iossa, S. (2007) Skeletal muscle subsarcolemmal mitochondrial dysfunction in high-fat fed rats exhibiting impaired glucose homeostasis. Int. J. Obes. (London) 31, 1596-1604

45. Hoeks, J., Briede, J. J., de Vogel, J., Schaart, G., Nabben, M., Moonen-Kornips, E., Hesselink, M. K. C., and Schrauwen, P. (2008) Mitochondrial function, content and ROS production in rat skeletal muscle: effect of high-fat feeding. FEBS Lett. 582, $510-516$

46. Bonnard, C., Durand, A., and Chauvin, M. A. (2008) Mitochondrial dysfunction results from oxidative stress in the skeletal muscle of diet-induced insulin-resistant mice. J. Clin. Invest. 118, $789-800$

47. Turner, N., Bruce, C. R., Beale, S. M., Hoehn, K. L., So, T., Rolph, M. S., and Cooney, G. J. (2007) Excess lipid availability increases mitochondrial fatty acid oxidative capacity in muscle: evidence against a role for reduced fatty acid oxidation in lipid-induced insulin resistance in rodents. Diabetes 56, 20852092

48. Zhang, D., Liu, Z. X., Choi, C. S., Tian, L., Kibbey, R., Dong, J. Cline, G. W., Wood, P. A., and Shulman, G. I. (2007) Mitochondrial dysfunction due to long-chain Acyl-CoA dehydrogenase deficiency causes hepatic steatosis and hepatic insulin resistance. Proc. Natl. Acad. Sci. U. S. A. 104, 17075-17080

49. Handschin, C., Choi, C. S., Chin, S., Kim, S., Kawamori, D. Kurpad, A. J., Neubauer, N., Hu, J., Mootha, V. K., Kim, Y. B. Kulkarni, R. N., Shulman, G. I., and Spiegelman, B. M. (2007) Abnormal glucose homeostasis in skeletal muscle-specific PGClalpha knockout mice reveals skeletal muscle-pancreatic beta cell crosstalk. J. Clin. Invest. 117, 3463-3474

50. Wredenberg, A., Freyer, C., Sandstrom, M. E., Katz, A., Wibom, R., Westerblad, H., and Larsson, N. G. (2006) Respiratory chain dysfunction in skeletal muscle does not cause insulin resistance. Biochem. Biophys. Res. Commun. 350, 202-207

51. Pospisilik, J. A., Knauf, C., Joza, N., Benit, P., Orthofer, M., Cani, P. D., Ebersberger, I., Nakashima, T., Sarao, R., Neely, G., Esterbauer, H., Kozlov, A., Kahn, C. R., Kroemer, G., Rustin, P., Burcelin, R., and Penninger, J. M. (2007) Targeted deletion of AIF decreases mitochondrial oxidative phosphorylation and protects from obesity and diabetes. Cell 131, $476-491$

Received for publication April 30, 2008 Accepted for publication June 26, 2008. 